\title{
Clinical and laboratory profile of systemic lupus erythematosus patients at a rural tertiary centre in South-South Nigeria: experience from a new rheumatology clinic
}

\author{
Airenakho Emorinken ${ }^{1}$, Mercy Ofunami Dic-ljiewere ${ }^{1}$, Cyril Oshomah Erameh ${ }^{1}$, \\ Asuwemhe Johnson Ugheoke ${ }^{1,2}$, Oluwaseun Remi Agbadaola ${ }^{1}$, Folasade Ojuolape Agbebaku ${ }^{1}$ \\ ${ }^{1}$ Department of Medicine, Irrua Specialist Teaching Hospital, Edo State, Nigeria \\ ${ }^{2}$ Department of Medicine, Ambrose Alli University, Ekpoma, Edo State, Nigeria
}

\begin{abstract}
Objectives: Systemic lupus erythematosus (SLE) is an autoimmune disorder with a poorly understood aetiology. It predominantly affects females and has a variety of clinical manifestations. In Nigeria, there are limited data on the prevalence and burden of the disease. This study aimed to determine the clinical and laboratory profiles of SLE patients seen in a new rheumatology clinic in South-South Nigeria.

Material and methods: This was a retrospective cross-sectional study conducted over five years (January 2016 to December 2020). The case files of patients that satisfied the diagnosis of SLE were reviewed. The diagnosis was based on the 1997 update of the American College of Rheumatology revised criteria for the classification of SLE. The sociodemographic, clinical, and immunological data were extracted from case records. Data analysis was carried out using IBM SPSS statistics ${ }^{\circledR} 2012$ version 21.0. Results: Fifty-two patients were diagnosed with SLE, giving a frequency of $4.7 \%$. Forty-seven $(90.4 \%)$ of the study participants were females, with a female-to-male ratio of $9.4: 1$. The mean age of the study group was 28.42 years. The mean duration of disease before diagnosis was 4.04 months with a range of 1-15 months. The patients had various organ system manifestations, with polyarthritis being the commonest (86.5\%). Others included mucocutaneous (78.8\%), haematological (69.2\%), serositis (40.4\%), renal (38.5\%), and neurological (25\%) manifestations. Antinuclear antibody (ANA) assay and anti-double-stranded DNA were positive in $100 \%$ and $69.2 \%$ of patients, respectively. All patients were placed on steroids, and $96.2 \%$ had hydroxychloroquine. None of the patients were on biologic disease-modifying antirheumatic drugs.

Conclusions: This study's results are consistent with data from other African countries. To fully understand the burden and epidemiology of SLE in Nigeria, a larger prospective study is needed.
\end{abstract}

Key words: systemic lupus erythematosus, autoantibody, clinical and laboratory profile.

\section{Introduction}

Systemic lupus erythematosus (SLE) is a chronic inflammatory autoimmune disorder with a variety of clinical presentations and a poorly understood aetiology [1]. It is characterized by immunologically induced, clinical, and serological phenomena and follows a relapsing and remitting course. The female-to-male ratio is $9.4: 1$, and females with a peak age of 20-40 years are more likely to develop SLE [2]. Systemic lupus erythematosus has a complex pathogenesis that includes genetic, immunological, and environmental influences, all of which affect the appearance, progression, and outcome of the disease [3].

There are varying reports on the prevalence and incidence of SLE, with the highest rates of 23.2/100,000

Address for correspondence:

Airenakho Emorinken, Division of Rheumatology, Department of Medicine, Irrua Specialist Teaching Hospital, PMB 08, Irrua, Edo State, Nigeria, e-mail: emosairen@gmail.com

Submitted: 11.06.2021; Accepted: 08.11 .2021 
person-years in North America and the lowest rates of 0.3/100,000 person-years in Africa. The occurrence and clinical presentation of SLE are likely to be influenced by genetic, environmental, sociodemographic, and sociocultural factors [4].

The disease was initially thought to be rare and less common among Negro Africans, due to immune system disruption caused by multiple parasitic infections [5, 6]. This contrasts with the fact that it is common among African Americans [7, 8]. The seemingly low incidence rate of SLE in Negro Africans can be attributed to low disease detection - especially in primary health care settings, restricted access to testing equipment, underdiagnosis as a result of limited access to health services, and an insufficient number of specialist doctors [9]. However, recent data, as well as experience from several centres in Africa, shows an increasing occurrence of $\operatorname{SLE}[5,9]$. A major impediment to understanding disease characteristics and establishing a strong SLE knowledge base in Nigeria is the scarcity of epidemiological data and the absence of disease registries.

Systemic lupus erythematosus manifests in a variety of ways, depending on ethnic and racial characteristics. According to data from the United Kingdom, musculoskeletal/cutaneous manifestations affect $85 \%$ of patients [10]. In a study conducted in the United States, Afro-American patients were found to have higher rates of nephritis, discoid rashes, anti-ribonucleoprotein (anti-RNP), and anti-Smith (anti-Sm) antibodies. Photosensitivity and oral ulcers, on the other hand, were less common [11]. Arthritis was the most common manifestation, and cardiac disease was the least common in a study done in Western India [12]. In a Zimbabwean study, renal involvement was more common while serositis and photosensitivity were less common than in the United States [13]. Lymphopaenia (48\%) was the commonest haematological abnormality [13].

In Nigeria, information is scarce regarding the profile, prevalence, and incidence of SLE. However, Adelowo et al. [14] found the frequency of SLE to be $5.28 \%$ of 1250 rheumatic cases seen over 6 years in Southwest Nigeria, with polyarthritis being the most common presentation. This study aimed to determine the clinical and laboratory characteristics of SLE patients in a new rheumatology clinic in South-South Nigeria.

\section{Material and methods \\ Study design and population}

This was a retrospective cross-sectional study conducted over a 5-year period from January 2016 to December 2020. The study was carried out at the Irrua Specialist Teaching Hospital's rheumatology outpatient clinic. Irrua is the headquarters of the Esan central local government area of Edo State, in South-South Nigeria. The hospital is a tertiary referral centre that serves people in the surrounding towns and states.

The study population were patients who presented with rheumatological complaints at the clinic. The patient's medical records were identified and reviewed, and all the patients' who satisfied the 1997 update of the American College of Rheumatology revised criteria for the classification of SLE were selected for the study [15]. Patients with overlap syndromes were excluded from the study.

Irrua Specialist Teaching Hospital Health Research Ethics Committee ethical approval was obtained before commencement of the study.

\section{Data collection}

The medical records of patients who met the inclusion criteria were identified and thoroughly reviewed. The sociodemographic and clinical data, as well as laboratory parameters (complete blood count - CBC, erythrocyte sedimentation rate - ESR, kidney function test, urine analysis, and microscopy), were retrieved from the patients' case notes. The results of immunological assays like antinuclear antibody (ANA) assay, anti-double-stranded DNA (anti-dsDNA), anti-Sm antibody, and other autoantibodies that were available were also retrieved from the files. All data were anonymized before analysis. The antinuclear antibody test was performed using an indirect immunofluorescence assay with HEP-2 cells as a substrate, and the clinically significant titre was $\geq 1: 80$. Anti-dsDNA and autoantibodies to extractable nuclear antigens (ENA) (anti-Sm, anti-SSA, anti-SSB, anti-RNP) were studied by the enzyme-linked immunosorbent assay method. Values greater than $25 \mathrm{IU} / \mathrm{ml}$ and $18 \mathrm{IU} / \mathrm{I}$ were considered positive for anti-Sm and anti-dsDNA, respectively. The sera were all tested at the Synlab laboratories in Nigeria.

\section{Statistical analysis}

The data were entered and analysed using IBM SPSS statistics ${ }^{\circledR} 2012$ version 21.0, a commercially available statistical kit for social sciences. Continuous variables were presented as mean and standard deviation, and categorical variables as frequency and percentage.

\section{Results}

A total of 52 patients were diagnosed with SLE, accounting for $4.7 \%$ of the total number (1100) of rheumatological cases seen during the study period.

Table I summarises the sociodemographic characteristics of SLE patients. The mean age was $28.42 \pm 10.34$ 
Table I. Sociodemographic characteristics of the study population

\begin{tabular}{|c|c|}
\hline Variables & Frequency (\%) \\
\hline \multicolumn{2}{|l|}{ Gender } \\
\hline Male & $5(9.6)$ \\
\hline Female & $47(90.4)$ \\
\hline \multicolumn{2}{|l|}{ Age range [years] } \\
\hline $10-19$ & $10(19.2)$ \\
\hline $20-29$ & $19(36.5)$ \\
\hline $30-39$ & $15(28.8)$ \\
\hline $40-49$ & $5(9.6)$ \\
\hline $50-59$ & $3(5.8)$ \\
\hline Mean \pm SD & $28.42 \pm 10.34$ \\
\hline \multicolumn{2}{|l|}{ Marital status } \\
\hline Single & $34(65.4)$ \\
\hline Married & $18(34.6)$ \\
\hline \multicolumn{2}{|l|}{ Occupation } \\
\hline Unemployed & $8(15.4)$ \\
\hline Civil servant & $8(15.4)$ \\
\hline Student & $28(53.8)$ \\
\hline Trader/business & $8(15.4)$ \\
\hline \multicolumn{2}{|l|}{ Religion } \\
\hline Christian & $47(90.4)$ \\
\hline Islam & $5(9.6)$ \\
\hline \multicolumn{2}{|l|}{ Level of education } \\
\hline Primary & $3(5.8)$ \\
\hline Secondary & $22(42.3)$ \\
\hline Tertiary & $27(51.9)$ \\
\hline \multicolumn{2}{|c|}{ Duration of symptoms [months] } \\
\hline$<3$ & $22(42.3)$ \\
\hline$\geq 3$ & $30(57.7)$ \\
\hline Mean \pm SD & $4.04 \pm 3.10$ \\
\hline \multicolumn{2}{|c|}{ Family history of autoimmune diseases } \\
\hline Yes & $1(1.9)$ \\
\hline No & $51(98.1)$ \\
\hline
\end{tabular}

SD - standard deviation.

(range: $12-58$ ) years, with the most affected group being 20-29 years (36.5\%), followed by 30-39 years (28.8\%). There were 47 females and 5 males, resulting in a female-to-male ratio of $9.4: 1$. The mean duration of illness before diagnosis was $4.04 \pm 3.10$ months, and 1.9\% had a family history of an autoimmune disease.

Table II shows the clinical manifestations at the time of presentation. Arthritis was the commonest manifestation $(86.5 \%)$, followed by mucocutaneous manifestations (78.8\%), extreme fatigue (73.1\%), haematological
Table II. Clinical manifestations of systemic lupus erythematosus noted in the study cohort

\begin{tabular}{|lc|}
\hline Variable & Number (\%) \\
\hline Mucocutaneous & $41(78.8)$ \\
\hline Malar rash & $13(25)$ \\
\hline Discoid rash & $6(11.5)$ \\
\hline Photosensitive rash & $25(48.1)$ \\
\hline Bullous rash & $9(17.3)$ \\
\hline Alopecia & $23(44.2)$ \\
\hline Oral ulcers & $22(42.3)$ \\
\hline Musculoskeletal & $45(86.5)$ \\
\hline Arthritis & $45(86.5)$ \\
\hline Fever & $31(59.6)$ \\
\hline Fatigue & $38(73.1)$ \\
\hline Renal involvement & $20(38.5)$ \\
\hline Serositis & $21(40.4)$ \\
\hline Pericarditis & $8(15.4)$ \\
\hline Pleuritis & $13(25)$ \\
\hline Neurological & $13(25)$ \\
\hline Psychosis & $9(17.3)$ \\
\hline Headache & $11(21.2)$ \\
\hline Seizures & $6(11.5)$ \\
\hline Recurrent abortions & $6(11.5)$ \\
\hline Haematological & $36(69.2)$ \\
\hline Anaemia & $34(65.4)$ \\
\hline Haemolytic anaemia & $26(42.3)$ \\
\hline Leucopaenia & $18(34.6)$ \\
\hline Lymphopaenia & \\
\hline
\end{tabular}

manifestations (69.2\%), and fever (59.6\%). Renal and neurological involvement accounted for $38.5 \%$ and $25 \%$ of the study population, respectively.

The erythrocyte sedimentation rate ranged from 56 to $136 \mathrm{~mm} / \mathrm{hr}$ with a mean of $105.87 \pm 18.86 \mathrm{~mm} / \mathrm{hr}$. The mean packed cell volume (PCV) was $27.92 \pm 4.69 \%$ and ranged from 17 to $36 \%$. Thirty-four (65.4\%) patients had anaemia (PCV < 30). The mean white blood cell count was 3501/ $\mu$ l, with leukopaenia in 26 (50\%) patients, lymphopaenia in 32 (61.5\%), and thrombocytopaenia in 18 (34.6) patients. In 20 (38.5\%) of the patients, urinary abnormalities were present. Low complement was found in 28.8\% (15) and 25\% (13) for C4 and C3, respectively, in those who were tested. The laboratory features are presented in Table III.

The autoantibody profiles of the subjects are shown in Table IV. The antinuclear antibody was positive in all 
Table III. Laboratory features of the study population

\begin{tabular}{|c|c|c|}
\hline Variables & $\begin{array}{l}\text { Number } \\
\text { tested }\end{array}$ & $\begin{array}{l}\text { Positive } \\
\text { result (\%) }\end{array}$ \\
\hline Anaemia (Haematocrit [\%]) & 52 & $34(65.4)$ \\
\hline $\begin{array}{l}\text { Leucopaenia }[/ \mu l] \\
(<4000)\end{array}$ & 52 & $26(50)$ \\
\hline $\begin{array}{l}\text { Lymphopaenia }[/ \mu l] \\
(<1000)\end{array}$ & 52 & $32(61.5)$ \\
\hline $\begin{array}{l}\text { Thrombocytopaenia [/ } \mu l] \\
(<100,000)\end{array}$ & 52 & $18(34.6)$ \\
\hline $\begin{array}{l}\text { Elevated ESR }\left[\mathrm{mm} / 1^{\text {st }} \text { hour }\right] \text {, } \\
\text { Westergren }(>20)\end{array}$ & 52 & $52(100)$ \\
\hline Positive Coomb's Test & 52 & $22(42.3)$ \\
\hline $\begin{array}{l}\text { Elevated serum } \\
\text { creatinine }[\mathrm{mg} / \mathrm{dl}](>1.4)\end{array}$ & 52 & $21(40.4)$ \\
\hline $\begin{array}{l}\text { Urine abnormalities } \\
\text { Proteinuria (dipstick > 3+) } \\
\text { Urinary casts }\end{array}$ & 52 & $\begin{array}{l}20(38.5) \\
15(28.8)\end{array}$ \\
\hline \multicolumn{3}{|l|}{ Low Complement [g/l] } \\
\hline$C 3(<8)$ & 22 & $13(59.1)$ \\
\hline$C 4(<0.15)$ & & $15(68.2)$ \\
\hline
\end{tabular}

ESR - erythrocyte sedimentation rate.

Table V. Treatment regimen of the study population

\begin{tabular}{|lc|}
\hline Medications & Number of patients (\%) \\
\hline Glucocorticoids & $52(100)$ \\
\hline HCQ & $50(96.2)$ \\
\hline MMF & $17(32.7)$ \\
\hline AZA & $17(32.7)$ \\
\hline MTX & $3(5.8)$ \\
\hline CYC & $14(26.9)$ \\
\hline MMF + HCQ & $11(21.2)$ \\
\hline HCQ + AZA + CYC & $14(26.9)$ \\
\hline HCQ + AZA & $5(9.6)$ \\
\hline MTX + HCQ & $1(1.9)$ \\
\hline
\end{tabular}

AZA - azathioprine, CYC - cyclophosphamide, $H C Q$ - hydroxychloroquine, MMF-mycophenolate mofetil, MTX - methotrexate.

patients and ENA was found in $86.5 \%$ of the patients. Anti-dsDNA, anti-RNA, and anti-Sm were found in 69.2\%, $59.6 \%$, and $48.1 \%$ of the study population, respectively. The antinuclear antibody titre ranged from $1: 160$ to $>1$ : 5120, with 14 (26.9\%) having a tire of $1: 320$. The majority of the tested sera (55.8\%) had a speckled pattern, while $42.3 \%$ had a homogeneous pattern.

Corticosteroids were given to all patients, either orally as prednisolone, intravenous pulse methylprednisolone, or intraarticular steroids. In $96.2 \%$ of the subjects, hydroxychloroquine (HCQ) was prescribed, and no one had any biologic disease-modifying antirheumatic drugs
Table IV. Autoantibody profiles in the study population

\begin{tabular}{|c|c|c|}
\hline Autoantibodies & $\begin{array}{c}\text { Number } \\
\text { tested }\end{array}$ & $\begin{array}{c}\text { Positive } \\
\text { result (\%) }\end{array}$ \\
\hline ANA & 52 & $52(100)$ \\
\hline Anti-dsDNA & 52 & $36(69.2)$ \\
\hline Anti-Sm & 52 & $25(48.1)$ \\
\hline Anti-Ro & 52 & $19(36.5)$ \\
\hline Anti-La & 52 & $15(28.4)$ \\
\hline Anti-RNP & 52 & $31(59.6)$ \\
\hline ENA & 52 & $45(86.5)$ \\
\hline Antiphospholipid antibody & 31 & $7(22.6)$ \\
\hline LAC & & $5(16.1)$ \\
\hline$\underline{\mathrm{ACL}}$ & & $7(22.6)$ \\
\hline Anti- $\beta_{2}$-glycoprotein & & $7(22.6)$ \\
\hline ANA Staining pattern & 52 & \\
\hline Homogenous & & $22(42.3)$ \\
\hline Speckled & & $29(55.8)$ \\
\hline Not specified & & $1(1.9)$ \\
\hline \multicolumn{3}{|l|}{ ANA titre } \\
\hline Not specified & & $1(1.9)$ \\
\hline $1: 160$ & & $14(26.9)$ \\
\hline $1: 320$ & & $4(7.7)$ \\
\hline $1: 640$ & & $9(17.3)$ \\
\hline $1: 1280$ & & $10(19.2)$ \\
\hline $1: 2560$ & & $5(9.6)$ \\
\hline $1: 5120$ & & $5(9.6)$ \\
\hline$>1: 5120$ & & $4(7.7)$ \\
\hline
\end{tabular}

$A C L$ - anticardiolipin antibody, ANA - antinuclear antibody, anti-dsDNA - anti-double-stranded DNA, anti-La - anti-lupus anticoagulant, anti-RNP - anti-ribonucleoprotein, anti-Ro - anti-Sjögren'ssyndrome-related antigen A, anti-Sm - anti-Smith, ENA - extractable nuclear antigen $L A C$ - lupus anticoagulant.

(DMARDs). The patients' immunosuppressive therapy regimens are represented in Table $\mathrm{V}$.

\section{Discussion}

Systemic lupus erythematosus is a condition that affects females of reproductive age and has a wide range of clinical manifestations. Despite reports that SLE is rare in Negro Africans [5], several studies have suggested that the burden of SLE is higher than previously thought [9, 14, 16-19].

A total of 1100 patients were seen in the rheumatology clinic during the study period. Fifty-two patients satisfied the diagnosis of SLE, giving a frequency of $4.7 \%$. This frequency is comparable to that reported by Adelowo et al. [14]. The study reveals a $90.4 \%$ female predominance, a female-to-male ratio of $9.4: 1$, and an 
average age of 28.42 years. This further highlights the young age of presentation and the gender disparity in favour of females, as seen in other African and Indian studies [16, 18, 20]. However, 2 of our patients were above 50 years old. The use of oral contraceptives and postmenopausal hormones has been linked to the onset of SLE, implying that hormonal factors may play a role in its pathogenesis [21]. The average age at diagnosis is slightly lower, but it is similar to other African and Asian studies [16, 22, 23].

The most common manifestation was polyarthritis (86.5\%), which is consistent with a previous study by Adelowo et al. (87\%) in Southwest Nigeria [14]. Similar findings were observed in Kenya (90\%) [16], Uganda (69.9\%) [23], Sudan (85.5\%) [19], South Africa (90\%) [18], Morocco (82\%) [24], India (78\%) [25], and Tunisia (87.1\%) [26]. The cumulative frequencies of clinical and immunological profiles of SLE patients across Africa are represented in Table VI.

Fever was present in more than half of our study population. This is significant because the majority of these patients, particularly in rural areas such as ours, may have been seen in multiple peripheral facilities and most of the time had been treated for malaria and typhoid fever for weeks or months before their presentation. This often leads to a late diagnosis and organ complications.

Photosensitivity (48.1\%) was the commonest mucocutaneous manifestation in our series. Genga et al. [16] and Saigal et al. [12] reported comparable frequencies of $44 \%$ and $45 \%$, respectively, of photosensitivity. The findings from studies by Adelowo et al. [14] and Doualla et al. [27] reported frequencies as low as 9\% and 7.7\%, respectively. Reports from South Africa have also shown a decreased frequency of photosensitivity [28]. The reason for such relatively low numbers may be due to the dark skin of the African population. Malar rashes, which are more common in Caucasians [29], were reported in only $25 \%$ of our patients. This is similar to the figure of $21 \%$ in a previous study in Southwest Nigeria [14]. However, it has been reported at higher frequencies in Morocco $(68 \%)$ and Tunisia $(68.7 \%)[24,26]$.

Patients with SLE may not report oral ulcers because they are typically painless and may go unnoticed. In our series, oral ulcers were present in less than half of the study patients, which was the same as in other African studies $[14,16,30]$. Hair loss occured in $44.2 \%$ of our patients, which is similar to the findings by Adelowo et al. [14] in Southwest Nigeria. Findings from other studies have shown variable frequencies of alopecia ranging from 10.34 to $65.7 \%[20,31]$.

Neuropsychiatric lupus (NPSLE) was seen in one-quarter of the patients and was also found to be uncommon in some other studies in Africa and India [16, 24, 27, 31].
Headaches were the most common NPSLE symptoms, accounting for $21.2 \%$ of the study population, followed by psychosis (17.3\%) and seizures (11.5\%). Headache was also the most prominent NPSLE symptom in the studies by Adelowo et al. [14] and Talukdar et al. [20].

The incidence of renal disease in SLE varies depending on the population studied. Nephritis was found in $38.5 \%$ of our sample, and varying frequencies of $5.4 \%$ in Uganda [23], 24\% in Kenya [16], and $49.5 \%$ in Tunisia [26] have been reported. Higher incidences of lupus nephritis have been reported in other African studies $[13,19,32]$. Proteinuria, red blood cells, urinary casts, and abnormal blood chemistry were all features of kidney disease. For logistic reasons, 24-hour urine for protein measurement and creatinine clearance was not done in our study group. Renal biopsy was also not done for these patients, which may explain the relatively low frequency of nephritis in this study and possibly other African studies [16, 27]. Kidney biopsy for histology is rarely performed in poor resource centres in Nigeria and Sub-Saharan Africa [14].

As a result, staging of lupus nephritis is usually not possible. Renal involvement in SLE among Negro Africans may occur earlier and follow a more severe course. Early renal biopsy in lupus nephritis helps in classifying lesions and selection of effective corresponding therapies. However, the lack of readily available microscopy and immunofluorescence facilities, especially in poor resource areas, has made this impossible.

The use of ESR in addition to clinical features as a screening tool in rural settings is not out of place, especially in patients who may not immediately have the funds for serological investigations. In this study, the ESR was invariably elevated in all patients, with almost half of them having an ESR of over $100 \mathrm{~mm} / \mathrm{hr}$.

In our study, all patients had a positive ANA test. Most studies discovered comparable levels of ANA positivity, typically greater than $80 \%[14,16,24,27]$. Ekwom in Kenya [32] and Bongomin et al. in Uganda [23] reported prevalence rates of $76.9 \%$ and $75.8 \%$, respectively. These high rates have also been reported in European studies [33].

The antinuclear antibody assay is a highly sensitive test for SLE that is required to meet current diagnostic criteria for the disease [34]. Titres of 1: 640 and higher were found in $63.5 \%$ of our patients. Four patients had titres above 1 : 5120. The most frequently observed staining pattern was speckled, which is consistent with findings from a previous study in Southwest Nigeria [14]. A Saudi Arabian study discovered comparable results [35]. However, in India, the opposite was discovered, with a predominance of homogeneous staining [36].

The anti-dsDNA antibody is specific for SLE. AntidsDNA and anti-Sm antibodies were detected in 69.2\% 


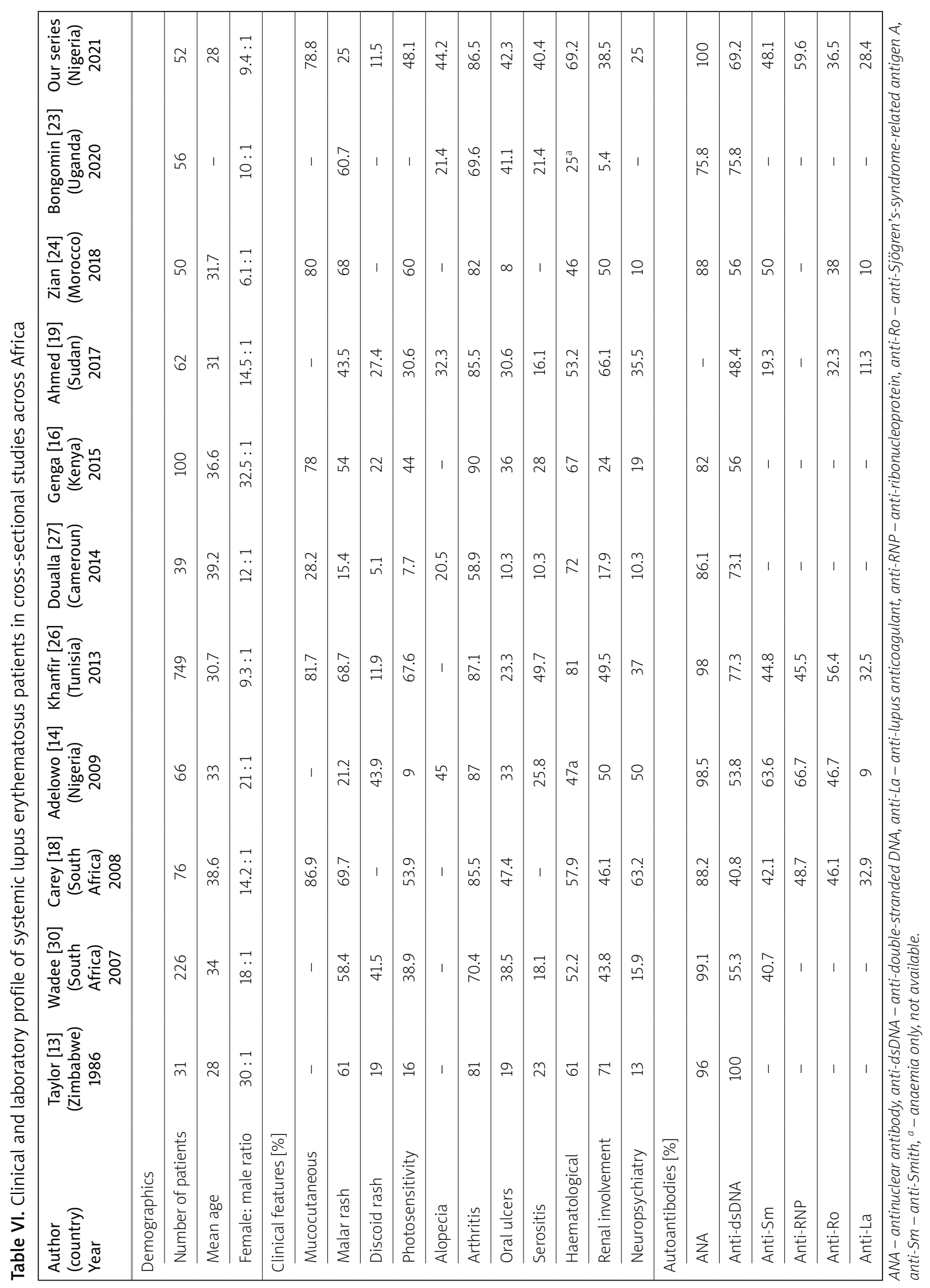


and $48.1 \%$ of patients in our study, respectively, and in $53.8 \%$ and $63.6 \%$ of patients in a similar study in Southwest Nigeria [14]. This discrepancy could be explained by the fact that we tested all patients in our study for these 2 autoantibodies, whereas Adelowo et al. [14] tested only a few patients at the time. The frequency of antidsDNA in our study is comparable to that observed in some African studies [26, 27] but significantly higher than that observed in South Africa [18, 30], Kenya [16], Sudan [19], and Morocco [24]. Patients with lupus are exclusively positive for anti-Sm autoantibodies. It has been demonstrated that its prevalence varies across populations. It has been reported to range between $19.3 \%$ in Sudan [19] and 75\% in Gabon [37].

The anti-RNP autoantibodies were also positive in $59.6 \%$ of our patients, which is comparable to the result of Adelowo et al. in Nigeria [14] and Khanfir et al. in Tunisia [26]. Anti-Sjögren's-syndrome-related antigen A (anti-Ro/SSA or anti-Ro) is said to be useful in SLE diagnosis, particularly in patients who test positive for ANA but not for anti-dsDNA [38]. In this study, 36.5\% of patients were positive for anti-Ro. This is consistent with other previously conducted studies [14, 19, 24]. However, Adelowo et al. [39] in 2012 observed a greater prevalence of anti-Ro antibodies (69.7\%) in a study evaluating autoantibodies in Nigerian lupus patients [39]. Previous research confirmed our findings about the low prevalence of anti-La/ SSB [19, 24, 26, 39]. Anti-La antibodies are more prevalent in Sjögren's syndrome, and their presence in SLE may be predictive of the presence of the syndrome.

Although antiphospholipid (APL) antibody testing was not performed on all patients in our study, the frequency of APL was low (22.6\%). Similar low prevalence rates have been recorded in previous research [37, 39]. In Cameroon, half of the patients were reported to be positive for anticardiolipin antibodies [27].

It is critical to state that the variance in prevalence of some autoantibodies observed across Africa may simply reflect the sensitivity of the various testing procedures utilized and possibly the cut-off levels of various populations. The high occurrence of autoantibodies, particularly ANA and anti-dsDNA, in this study supports the previous findings that Negros have a higher frequency of immunological markers associated with SLE than Caucasians [40].

Hydroxychloroquine is the most widely prescribed drug for lupus patients in Africa, as reported in studies by Genga et al. [16] (77\%), Doualla et al. [27] (69\%), and Ekwom [32] (92\%). A previous study by Adelowo et al. [14] in Southwest Nigeria in 2009 had very few patients placed on HCQ. This is because HCQ only became available in Nigeria a few years before the study. The majority (96.2\%) of our patients were on HCQ, and all the patients were on steroids. None of the patients were on biologics. This is due to unavailability and high costs. The high use of HCQ is attributable to the fact that it is readily available and inexpensive in our area. It has been approved for the treatment of SLE in compliance with international guidelines and it is shown to delay disease onset, decrease the frequency of flares, maintain remission, and decrease complication risks.

Other DMARDs used include azathioprine, mycophenolate mofetil, methotrexate, and cyclophosphamide, depending on the organ system's manifestation. Because SLE runs an aggressive course in Negro African patients, it is critical to start DMARDs as soon as possible. In Nigeria, there are issues of high default rates due to various cultural beliefs and unfulfilled expectations for a cure, as well as high management costs because most patients pay out of pocket due to poor insurance coverage. Therefore, the impact of the disease on the quality of life and socioeconomic effects can be determined by fully understanding the disease burden associated with SLE. This will make it easier to allocate resources to enhance the quality of life of people with SLE.

\section{Study limitations}

This study has several limitations, including a small study group, a predominantly student population, and our inability to perform kidney biopsies to evaluate patients with lupus nephritis. Additionally, its retrospective design precluded us from obtaining a great deal of information, such as treatment outcome evaluation. Because the data were collected from a single health facility, their generalizability may be limited.

To have a better understanding of the epidemiological features of SLE, a larger multicentre prospective study is needed. Another disadvantage is the inconvenience of obtaining serological testing, which is not routinely performed in public healthcare settings and must be obtained privately at the expense of the patient in our conditions.

\section{Conclusions}

Polyarthritis and mucocutaneous manifestations associated with elevated ESR and the presence of a high occurrence of autoantibodies (ANA/anti-dsDNA) seem to be useful in the diagnosis of lupus in this population. Knowledge of the characteristics of lupus in the Nigerian population will enable primary and secondary health care settings to make an early diagnosis and institute appropriate treatment. A larger multicentre prospective study is needed to validate our findings.

The authors declare no conflicts of interest. 


\section{References}

1. Tanaka Y. State-of-the-art treatment of systemic lupus erythematosus. Int J Rheum Dis 2020; 23: 465-471, DOI: 10.1111/ 1756-185X.13817

2. Ramírez Sepúlveda JI, Bolin K, Mofors J, et al. Sex differences in clinical presentation of systemic lupus erythematosus. Biol Sex Differ 2019; 10: 60, DOI: 10.1186/s13293-019-0274-2.

3. Choi J, Kim ST, Craft J. The pathogenesis of systemic lupus erythematosus - an update. Curr Opin Immunol 2012; 24 651-657, DOI: 10.1016/j.coi.2012.10.004.

4. Borchers AT, Naguwa SM, Shoenfeld Y, Gershwin ME. The geoepidemiology of systemic lupus erythematosus. Autoimmun Rev 2010; 9: A277-287, DOI: 10.1016/j.autrev.2009.12.008.

5. Adebajo A, Davis P. Rheumatic diseases in African blacks. Semin Arthritis Rheum 1994; 24: 139-153, DOI: 10.1016/s00490172(05)80007-1.

6. Greenwood BM. Autoimmune disease and parasitic infections in Nigerians. Lancet 1968; 2: 380-382, DOI: 10.1016/s01406736(68)90595-3.

7. Fessel WJ. Systemic lupus erythematosus in the Community. Incidence, prevalence, outcome, and first symptoms; the high prevalence in black women. Arch Int Med 1974; 134 1027-1035, DOI: 10.1001/archinte.1974.00320240061006.

8. Danchenko N, Satia JA, Anthony MS. Epidemiology of systemic lupus erythematosus: a comparison of worldwide disease burden. Lupus 2006; 15: 308-318, DOI: 10.1191/0961203306lu2305xx.

9. Adelowo OO, Bello MKN. Systemic autoimmune diseases: not so rare in black africans. rheumatology (Sunnyvale) 2014; 4 130, DOI: 10.4172/2161-1149.1000130.

10. Harvey AMG, Shulman LE, Tumulty PA, et al. Systemic lupus erythematosus: review of the literature and clinical analysis of 138 cases. Medicine (Baltimore) 1954; 33: 291-437, DOI: 10.1097/00005792-195412000-00001.

11. Cooper GS, Dooley MA, Treadwell EL, et al. Risk factors for development of systemic lupus erythematosus: allergies, infections, and family history. J Clin Epidemiol 2002; 55: 982-989, DOI: 10.1016/s0895-4356(02)00429-8.

12. Saigal R, Kansal A, Mittal M, Singh Y. Clinical profile of systemic lupus erythematosus patients at a tertiary care centre in Western India. J Indian Acad Clin Med 2011; 1: 27-32.

13. Taylor HG, Stein CM. Systemic lupus erythematosus in Zim babwe. Ann Rheum Dis 1986; 45: 645-648, DOI: 10.1136/ ard.45.8.645.

14. Adelowo OO, Oguntona SA. Pattern of systemic lupus erythematosus among Nigerians. Clin Rheumatol 2009; 28: 699-703, DOI: 10.1007/s10067-009-1139-6.

15. Hochberg MC. Updating the American College of Rheumatology revised criteria for the classification of systemic lupus erythematosus. Arthritis Rheum 1997; 40: 1725, DOI: 10.1002/ art.1780400928

16. Genga EK, Shiruli BC, Odhiambo J, et al. Clinical characteristics of patients with systemic lupus erythematosus in Nairobi, Kenya. Afr J Rheumatol 2015; 3: 62-66.

17. Ndiaye FS, Ka MM, Fall S, et al. Hematologic and immunologic signs of lupus: the experience of the hospital of Dakar. Sante 2011; 21: 143-148, DOI: 10.1684/san.2011.0265 [Article in French].
18. Carey R, Simmons S, Malherbe M, et al. Clinical features of patients with systemic lupus erythematosus (SLE) attending the SLE outpatient clinic at Universitas Hospital in Bloemfontein, South Africa. South Africa Fam Pract 2008; 50: 68-68c, DOI: 10.1080/20786204.2008.10873674.

19. Ahmed N, Shigidi M, Al Agib AN, et al. Clinical features and antinuclear antibodies profile among adults with systemic lupus erythematosus and lupus nephritis: A cross-sectional study. Pan Afr Med J 2017; 27: 14, DOI: 10.11604/pamj.2017.27.114.5981.

20. Talukdar D, Gogoi AP, Doley D, et al. The clinical and immunological profiles of systemic lupus erythematosus patients from Assam, North-East India. Indian J Rheumatol 2020; 15: 181-186, DOI: 10.4103/injr.injr_37_20.

21. Costenbader KH, Feskanich D, Stampfer MJ, Karlson EW. Reproductive and menopausal factors and risk of systemic lupus erythematosus in women. Arthritis Rheum 2007; 56: 1251-1262, DOI: 10.1002/art.22510

22. Jakes RW, Bae SC, Louthrenoo W, et al. Systematic review of the epidemiology of systemic lupus erythematosus in the Asia-Pacific region: prevalence, incidence, clinical features, and mortality. Arthritis Care Res (Hoboken) 2012; 64: 159-168, DOI: 10.1002/acr.20683.

23. Bongomin F, Sekimpi M, Kaddumukasa M. Clinical and immunological characteristics of 56 patients with systemic lupus erythematosus in Uganda. Rheumatol Adv Pract 2020; 4: rkaa001, DOI: 10.1093/rap/rkaa011.

24. Zian Z, Maamar M, El Aouni M, et al. Immunological and clinical characteristics of systemic lupus erythematosus: a series from Morocco. Biomed Res Int 2018; 2018: 3139404, DOI: 10.1155/2018/3139404.

25. Malaviya AN, Singh RR, Singh YN, et al. Prevalence of systemic lupus erythematosus in India. Lupus 1993; 2: 115-118, DOI: 10.1177/096120339300200209.

26. Khanfir MS, Houman MH, Cherif E, et al. TULUP (TUnisian LUPus): a multicentric study of systemic lupus erythematosus in Tunisia. Int J Rheum Dis 2013; 16: 539-546, DOI: 10.1111/ 1756-185X.12152.

27. Doualla M, Luma Namme H, Ashuntantang G, et al. Clinical presentation, treatment and outcome of patients with SLE at a rheumatology clinic in Douala, Cameroon. Heal Sci Dis 2014; 15: 1-5.

28. Jacyk WK, Steenkamp KJ. Systemic lupus erythematosus in South African blacks: prospective study. Int I Dermatol 1996; 35: 707-710, DOI: 10.1111/j.1365-4362.1996.tb00642.x.

29. Cameron JS. Systemic Lupus erythematosus. In: Immunologic Renal Disease, Nielson EG, Couser WG (eds), $2^{\text {nd }}$ ed. Philadelphia, Lippincott Raven 2001, 1057-1104.

30. Wadee S, Tikly M, Hopley M. Causes and predictors of death in South Africans with systemic lupus erythematosus. Rheumatology (Oxford) 2007; 46: 1487-1491, DOI: 10.1093/rheumatology/kem180.

31. Agrawal SR, Tiewsoh I, Rajput A, Jain A. A cross-sectional hospital based study of clinical and immunological profile of systemic lupus erythematosus patients from central rural India. Indian J Allergy Asthma Immunol 2013; 27: 33-37, DOI: 10.4103/0972-6691.116614. 
32. Ekwom PE. Systemic lupus erythematosus (SLE) at the Kenyatta National Hospital. Clin Rheumatol 2013; 32: 1215-1217, DOI: 10.1007/s10067-013-2217-3.

33. Cervera R, Khamashta MA, Font J, et al. Systemic lupus erythematosus: clinical and immunologic patterns of disease expression in a cohort of 1,000 patients. The European Working Party on Systemic Lupus Erythematosus. Medicine (Baltimore) 1993; 72: 113-124.

34. Aringer M, Costenbader K, Daikh D, et al. 2019 European League against Rheumatism/American College of Rheumatology classification criteria for systemic lupus erythematosus. Arthritis Rheumatol 2019; 71: 1400-1412, DOI: 10.1002/ art.40930.

35. Almogren A. Anti-double stranded antibody. Association with titers and fluorescence patterns of anti-nuclear antibody in systemic lupus erythematosus. Saudi Med J 2010; 31: 32-36.

36. Sebastian W, Roy A, Kini U, Mullick S. Correlation of antinuclear antibody immunofluorescence patterns with immune profile using line immunoassay in the Indian scenario. Indian
J Pathol Microbiol 2010; 53: 427-432, DOI: 10.4103/03774929.68262.

37. Gbané-Koné M, Ouattara B, Djaha KJM, et al. Autoantibodies in systemic lupus erythematosus, on black African subject, in Abidjan. Open J Rheumatol Autoimmune Dis 2015; 5: 28-35, DOI: 10.4236/ojra.2015.52006.

38. Sánchez-Guerrero J, Lew RA, Fossel AH, Schur PH. Utility of anti-Sm, anti-RNP, anti-Ro/SS-A, and anti-La/SS-B (extractable nuclear antigens) detected by enzyme-linked immunosorbent assay for the diagnosis of systemic lupus erythematosus. Arthritis Rheum 1996; 39: 1055-1061, DOI: 10.1002/ art.1780390626.

39. Adelowo OO, Ojo O, Oduenyi I. Autoantibodies in Nigerian lupus patients. Afr J Med Sci 2012; 41: 177-181.

40. Tikly M, Burgin S, Mohanlal P, et al. Autoantibodies in black South Africans with systemic lupus erythematosus: spectrum and clinical associations. Clin Rheumatol 1996; 15: 261-265, DOI: 10.1007/BF0222970. 